\title{
El Acuerdo entre el Mercosur y la Unión Europea. Estudio Integral de sus cláusulas y efectos. GHIOTTO, Luciana y ECHAIDE, Javier. Ed. CLACSO Fundación Rosa Luxemburgo Greens/EFA, 2020
}

El trabajo en español elaborado por los autores Luciana Ghiotto y Javier Echaide, titulado "El Acuerdo entre el MERCOSUR y la Unión Europea. Estudio integral de sus cláusulas y efectos", publicado en febrero del 2020, deja de manifiesto una fuerte crítica por parte de los autores, atravesada por un firme enfoque ambientalista $y$ socioeconómico, al Acuerdo entre el MERCOSUR y la Unión Europea.

Ghiotto, investigadora del Consejo Nacional de Investigaciones Científicas y Técnicas (CONICET) en Argentina y profesora en la Universidad Nacional de San Martín (UNSAM) y Echaide, también investigador del CONICET y profesor en la Facultad de Derecho de la Universidad de Buenos Aires (UBA) y de la Universidad Nacional de Lomas de Zamora (UNLZ), se muestran preocupados por los impactos medioambientales, económicos y sociales que este instrumento de cooperación económica puede causar en las economías del MERCOSUR y, particularmente, en la Argentina.

En términos generales, los argumentos centrales sobre los cuales apoyan sus críticas al Acuerdo son, principalmente, el daño al medio ambiente que generará su entrada en vigor y el efecto negativo en las economías locales. Por un lado, los autores mencionan que la importación de mayor cantidad de carne y otros productos agrícolas, por parte de los países europeos, significará un incremento de emisiones, mayor deforestación, contaminación del suelo y el atropello de los derechos humanos, mientras que, del lado del MERCOSUR, se pondrán en riesgo de dislocación a las cadenas de valor regionales y las economías.

Además, sostienen que lo negociado no sólo no está a la altura de la exigencia de las normas laborales y medioambientales vinculantes, sino que, también, este Acuerdo, al igual que el resto de los acuerdos comerciales negociados por los gobiernos, no cuenta con la participación democrática de los ciudadanos. Por el contrario, el mismo fue llevado a cabo por los gobiernos desconectados de la sociedad y ésta es una preocupación muy grande que demuestran los autores en su obra. En este sentido, advierten que hay nulos estudios del impacto para las economías, las sociedades y el medio ambiente sobre la implementación de este tipo de instrumentos, lo cual, en cierta medida, está acompañado por la carencia de criterio, en los gobernantes, sobre su cancelación en caso de que los mismos no sean sostenibles. De hecho, los autores, potencian esta idea con la afirmación de que varios funcionarios gubernamentales y negociadores del Acuerdo MERCOSURUE han mencionado, de manera extra oficial, que el mismo no traería ganancias para la Argentina y que la negociación se hizo, prácticamente, a ciegas.

El trabajo se compone de una introducción, en donde los autores describen el contexto en el que se firma el Acuerdo y anticipan su mirada crítica al mismo. En ésta destacan una Unión Europea en proceso de apertura compulsiva de su comercio, mediante la firma y negociación de acuerdos comerciales (siendo, la misma, el segundo socio comercial de Argentina, luego de Brasil, y el primero en inversiones extranjeras directas) y, como contracara, una guerra comercial entre Estados Unidos y China, en donde el primero pregona un proteccionismo económico nacional. 
Además, en la primera parte hacen un detallado recorrido sobre el proceso de negociación que tuvo este instrumento comercial, mediante una puntualización cronológica prolija, lo cual es calificado, por los autores, como "las negociaciones comerciales más largas del mundo".

En el segundo capítulo trabajan específicamente sobre el pilar comercial y, desde el comienzo, los autores resaltan las asimetrías económicas que hay entre los países de la Unión Europea y los del MERCOSUR, lo cual aseguran que es un dato sustancial para evaluar el impacto de la liberalización comercial entre ambos bloques. A modo de ejemplo, retoman datos del Observatorio de la Coyuntura Internacional y la Política Exterior (OCIPEX) y aseguran que el PBI de Alemania es igual al de Argentina, Brasil, Uruguay y Paraguay combinados. La gran asimetría radica en el tipo de bienes que exporta la Unión Europea y los que vende el MERCOSUR. Mientras que los primeros producen, fundamentalmente, bienes con valor agregado medio y alto, los segundos, tienen sus exportaciones primarizadas.

Por este desequilibrio, la liberalización, por parte de la UE, del $100 \%$ del comercio de bienes "para uso industrial no genera beneficios claros para las economías del bloque sureño, ya que sus principales exportaciones a Europa corresponden a productos primarios y sus derivados. Esto es puesto de manifiesto por Ghiotto y Echaide en un conciso cuadro aclarativo que grafica tal desequilibrio.

Siguiendo esta línea argumentativa, señalan, firmemente, que el efecto negativo del Acuerdo conllevará, no sólo a una mayor primarización de las economías sureñas y al reemplazo del comercio interindustrial entre países del MERCOSUR, sino también, a la sustitución del comercio local de productos procesados de origen agrícola por productos europeos, como el aceite de oliva o los quesos.

Otro gran desequilibrio entre los bloques, que los autores destacan, radica en la importancia del otro socio para cada uno de ellos: el MERCOSUR representa sólo el $1,3 \%$ de las ventas de la UE mientras que, por su parte, la UE abarca el $21 \%$ de las exportaciones mercosureñas.

Luego de marcar estas grandes asimetrías entre ambas partes, subdividen minuciosamente el análisis del pilar comercial en los diferentes rubros analizados: bienes industriales; sector automotriz; bienes agrícolas; "productos sofisticados", tales como el vino, licores, aceite de oliva, fruta fresca, duraznos enlatados, conservas de tomate, malta, papas congeladas, chocolates, galletas y refrescos; carnes de vacuno, cerdo y aves de corral; "otros sectores importantes", como el lácteo y olivinícola.

Uno de los puntos más importantes en el que ambos hacen foco y advierten, es en el hecho de que, si bien el capítulo agrícola no fue festejado por los sectores productores europeos, la letra de lo acordado permite a Europa mantener subvenciones agrícolas a través de la Política Agrícola Común (PAC) lo cual le otorga una mejora en la competitividad de los productos europeos, afectando las exportaciones del MERCOSUR a dicho destino. No obstante, reconocen que los grandes ganadores del acuerdo son los empresarios ligados a la agro-exportación del MERCOSUR y ejemplifican los sectores que, a su criterio, van a verse beneficiados.

En el tercer capítulo, los autores comienzan con un breve y preciso recorrido por las barreras técnicas al comercio. La primera parte del mismo es fundamentalmente descriptiva y, en ésta, se identifican algunos conceptos claves como, por ejemplo, el de stakeholders y de transparencia.

Más adelante reflexionan sobre los efectos de la inclusión, en el Acuerdo, de la 
facilitación del comercio y los obstáculos técnicos al mismo alertando, con argumentos sólidos, que esto podría implicar que los Estados cedan en su proceso de toma de decisiones al tener que incorporar los requerimientos del sector privado en el momento de adoptar nuevas regulaciones. Esta cuestión preocupa a los autores, pues la tendencia a la homogeneización de todas las regulaciones vinculadas al comercio y aduana puede reducir los estándares de protección de los consumidores y del medio ambiente y puede, también, conllevar a la disminución de estándares sanitarios y fitosanitarios.

Como contracara, observan que el sector privado se verá favorecido de la reducción de costos y tiempos de operación. La mayor intranquilidad de los autores, en relación a este tema, es el hecho de que este efecto es pasado por alto en los estudios de impacto ya que se consideran a estos capítulos como puramente técnicos.

Asimismo, hacen un breve repaso sobre el capítulo de medidas sanitarias y fitosanitarias (MSF) retomando el planteamiento de la creación de un subcomité cuyas decisiones no estarán sujetas a control democrático ya que el Acuerdo entre ambos bloques dejó de lado esta cuestión.

En el estudio que presentan sobre el capítulo de Diálogos retoman un análisis hecho por Carla Poth, en 2019, en donde se considera que la inclusión del capítulo sobre Biotecnología Agrícola hace más flexible la importación, por parte de la UE, de productos con niveles más altos de Organismos Genéticamente Modificados, normalizando el modelo de biotecnología agrícola en el MERCOSUR. Según los autores, este capítulo carece de certezas y se considera inadecuado por dejar de lado el principio precautorio. Siguiendo esta línea argumentativa, y considerando que el sector de la Agroindustria en el MERCOSUR es el que sale más beneficiado del Acuerdo entre las partes, los autores manifiestan, con criterio, su preocupación por las asimetrías regulatorias entre ambos socios en relación a los procesos productivos y a la falta de regulación de éstos. Consideran que existe un vacío legal en los países del sur en lo concerniente al cumplimiento de medidas sanitarias y fitosanitarias. El Acuerdo negociado no contribuye a resolver este problema, por el contrario, el capítulo de MSF es débil ya que son las propias autoridades competentes de los países exportadores las que deben llevar a cabo este tipo de controles, transformándose, este tema, en extremadamente sensible para los consumidores europeos.

En el cuarto capítulo, sobre comercio y desarrollo sostenible, Ghiotto y Echaide comienzan resaltando la importancia de la inclusión de esta temática en el Acuerdo y se muestran preocupados por la misma. Retomando la opinión de Adriana Erthal Abdenur, sostienen que la debilidad de este capítulo del Acuerdo radica en el hecho de que no se establecen mecanismos exigibles para mitigar el cambio climático ni, tampoco, se establecen sanciones para los Estados que no cumplan las obligaciones del Acuerdo de París, a pesar de que colocaron al mismo como vinculante para poder llevar a cabo asuntos comerciales.

Además de lo mencionado, advierten, con certeros motivos, que el Acuerdo conducirá a incrementar la emisión de gases de efecto invernadero y detallan, con cifras, la generación actual de toneladas de $\mathrm{CO} 2$ por el comercio entre MERCOSUR y UE avisando que el incremento de exportaciones e importaciones entre los bloques generará, inevitablemente, un aumento de dichas toneladas. En este sentido, los impactos negativos mencionados por los autores son muchos y todos son congruentes y claramente detallados en el trabajo.

Otro tema que consideran relevante, y que fue incluido en la letra del Tratado, es un artículo sobre información técnica y científica (el número 10), mediante el cual se 
establece el "Principio Precautorio", ya trabajado por ellos con anterioridad, que permite a la UE tomar medidas en caso de sospecha de que ciertos productos impliquen riesgo para la salud pública y el medioambiente, a pesar de que el MERCOSUR estaba en desacuerdo. En el documento, Ghiotto y Echaide exponen con claridad la postura del MERCOSUR al respecto y reflexionan sobre la terminología utilizada en el instrumento comercial criticando al mismo la libre interpretación a la cual queda abierta este tema.

En el quinto apartado, los autores hacen un recorrido sobre el capítulo de servicios que tiene el Acuerdo entre MERCOSUR y UE haciendo una detallada descripción de estos temas e incorporando puntos de vistas sobre algunas de sus cláusulas. Un ejemplo de ésto es la crítica al abordaje del capítulo de movimiento de capital que, si bien está incluido, para los autores, no se desarrolla a fondo al considerarse un tema en el que los bloques son complementarios. Otro ejemplo, es el hecho de que, los Estados, terminarán gravando a sus propios ciudadanos por utilizar los servicios electrónicos, sin tener la posibilidad de gravar a las empresas que obtienen ganancias de esto.

En el sexto capítulo del libro se ocupan del mercado de compras gubernamentales y licitaciones que incluye el acuerdo advirtiendo, de entrada, que los mercados nacionales se verán expuestos a un nuevo nivel de competencia en el que, competidores nacionales de los países del MERCOSUR y europeos tendrán igualdad de condiciones. Los autores ejemplifican con sensatez esta opinión y dejan de manifiesto su inquietud en relación a la exposición que van a tener que enfrentar las empresas del bloque sureño frente a la competencia europea.

En el capítulo siete, Ghiotto y Echaide hacen un breve recorrido sobre la inclusión de los derechos de propiedad intelectual en el acuerdo birregional $\mathrm{y}$, dentro de todos los temas que abarca el capítulo, analizan los siguientes tres como críticos y problemáticos: patentes medicinales; tratamiento de variedades vegetales e indicaciones geográficas (IG). En relación al último tópico, dentro del análisis hacen una reflexión sobre el alcance de las indicaciones geográficas, contrastando las aceptadas por MERCOSUR a la UE en comparación con las aceptadas por otros socios comerciales de la Unión entendiendo que la UE protege más sus productos con este acuerdo que con otros.

En el capítulo ocho, abordan temas que clasifican como "Otros" y que no fueron trabajados a lo largo del documento. Entre ellos, Pymes, para el cual advierten que falta una parte del capítulo sobre una financiación especial para las empresas del MERCOSUR con el objetivo de apoyarlas a poder entrar en el mercado de la UE, lo que consideran débil por no comprender temas importantes como, por ejemplo, el impacto de la liberalización para las Pymes, ni el tema de las asimetrías entre ellas; empresas estatales, capítulo que mencionan como de importancia; el de solución de controversias, detallando las consultas de buena fe, la mediación, los paneles de arbitraje y el código de conducta para árbitros. Finalizan este capítulo con una pequeña mención al Comité de Asociación y Comités Especiales altamente políticos que harán las discusiones del acuerdo.

En el capítulo final enumeran, de manera ordenada, sus conclusiones, las cuales son transversales y coherentes con todos los tópicos abordados y analizados en la obra, tales como la falta de democracia y transparencia en las negociaciones del Acuerdo; las asimetrías económicas entre ambos bloques que quedan profundizadas con este instrumento y que bien detallan y ejemplifican al analizar el pilar comercial del mismo; el riesgo en el cual quedan los estándares ambientales y de salud con la estandarización de las regulaciones y, por último, el daño al medioambiente que generará el aumento del comercio entre los bloques, sobre todo, la mayor cantidad de emisiones de $\mathrm{CO} 2$ y el peligro de deforestación. Todas estas conclusiones alcanzadas por los autores contribuyen 
a su postura crítica al Acuerdo y se encuentran minuciosamente respaldadas a lo largo del trabajo aportando estudios, referencias de investigaciones complementarias y datos estadísticos que le otorgan autenticidad y acierto.

Sabrina Ravasio, Lic. en Relaciones Internacionales (UNR). Magister en Cooperación e Integración Internacional (CEI, CERIR, UNR). Correo electrónico: ravasiosabrina@gmail.com

\section{Cómo citar}

Ravasio, S. (2020). Reseña GHIOTTO, Luciana y ECHAIDE, Javier (2020), El Acuerdo entre el Mercosur y la Unión Europea. Estudio Integral de sus cláusulas y efectos. Ed. CLACSO Fundación Rosa Luxemburgo Greens/EFA. Revista Integración $Y$ Cooperación Internacional, 31 (jul-dic), 63-67 